\title{
REPRESENTASI GENDER DALAM BUKU TEKS BIPA
}

\author{
Gatut Susanto \\ Universitas Negeri Malang \\ email: gatutsusanto@gmail.com
}

\begin{abstract}
(Title: Gender Representation in The BIPA Textbook). This article aims to describe the gender representation in the Indonesian language for foreign speakers (BIPA) textbook. The method used in this research is descriptive qualitative. The data were textual words and pictures that showing gender identity. Data were collected from BIPA textbook called Let's Speak Indonesian: Ayo Berbahasa Indonesia 1, which is well known as Ayo 1. Data gathered by reading the textbook, marking, classifying, and calculating gender identity markers. By using gender identity as the parameter, data were analyzed by reducing, presenting, calculating the percentage of gender identity representations, interpreting and explaining the representation of the gender. The findings revealed that the representation of female gender in the Ayo 1 textbook has a greater percentage than male gender where female's identities are more highlighted than male identities. Thus, it is concluded that based on the percentage of visual gender, the Ayo 1 textbook represented the gender equality because it's reflects less domination of male over female. This empirical evidence suggests that future BIPA textbook designers need to be aware of the importance of gender representation issues in developing BIPA textbook.
\end{abstract}

Keywords: BIPA textbook, gender identity, gender representation

\section{PENDAHULUAN}

Gender adalah kajian ilmu sosial humaniora yang memandang identitas laki-laki dan perempuan bukan dari jenis kelamin secara biologis, tetapi memandang mereka dari perannya. Secara sederhana peran laki-laki dan perempuan dapat dijelaskan dengan konsep lakilaki boleh melakukan apa dan perempuan boleh melakukan apa di masyarakat. Peran laki-laki dan perempuan dibangun oleh persepsi sosial dan budaya di masyarakat (Keplinger, Kowal \& Mäkiö, 2016). Peran laki-laki dan perempuan secara sosial budaya sering tidak seimbang. Di masyarakat, peran laki-laki lebih menonjol dan lebih dominan daripada peran perempuan. Ketidaksetaraan peran laki- laki dan perempuan ini mengarah kepada ketidakadilan. Ketimpangan peran laki-laki dan perempuan tersebut disebabkan oleh bias gender. Oleh karena itu, lewat gerakan feminisme, para aktivis Amerika dan Eropa memperjuangkan keadilan bagi kaum perempuan. Gerakan feminisme memperjuangkan hak perempuan untuk diperlakukan adil, seimbang, dan setara dengan laki-laki.

Representasi kesetaraan gender dapat diamati melalui pemakaian bahasa yang menunjukkan identitas gender laki-laki dan gender perempuan. Oleh karena itu, penelitian tentang representasi gender sering dikaitkan dengan bahasa (Lakoff, 2003). Penelitian representasi gender dalam kaitannya dengan bahasa 
biasanya menitikberatkan kajiannya pada teks, misalnya buku-buku pelajaran. Salah satu buku pelajaran yang sering dikaji adalah buku pelajaran bahasa. Dalam penelitian representasi gender dengan objek buku pelajaran bahasa, peneliti mengeksplorasi bahasa dan gambar-gambar visual yang menunjukkan identitas gender (Jannati, 2015; Liu, 2013). Dijelaskan lebih lanjut Lestariyana, Widodo dan Sulistiyo (2020) bahwa bentuk visual representasi gender dapat diamati dari teks dan gambar yang mencerminkan gender. Sementara itu, persentase gender perempuan dan lakilaki baik secara visual teks maupun gambar tercermin pada jumlah dan frekuensi munculnya identitas penanda gender perempuan dan laki-laki.

Dalam buku teks BIPA, identitas gender juga disajikan secara visual teks dan gambar. Penyajian identitas gender secara visual teks berwujud paparan verbal berupa bahasa. Bahasa yang menunjukkan identitas gender tercermin pada pemakaian nama-nama orang, kata benda, kata ganti orang, dan kata sifat penjelas gender (Bahman \& Rahimi, 2010; Jannati, 2015). Dalam buku teks bahasa Indonesia termasuk buku teks BIPA, identitas gender dapat ditelusuri antara lain melalui manifestasi pemakaian 1) nama-nama orang, 2) sapaan, 3) gelar penghormatan, 4) kata sifat, 5) kata benda, dan 6) kata kerja. Nama-nama Siti, Fitria, dan Fatimah menunjukkan gender perempuan, sedangkan Joko, Putro, Satriyo menanda-kan gender laki-laki. Kata sapaan Mbak menunjukkan sapaan kepada perempuan dan sapaan Mas menunjukkan sapaan kepada lakilaki.

Gelar penghormatan Roro untuk gelar penghormatan kepada perempuan dan Raden untuk laki-laki. Pemakaian kata sifat cantik untuk perempuan dan tampan untuk laki-laki. Kata benda daster, rok, dan kebaya mengarah kepada gender perempuan, sedangkan sarung, songkok, baju koko mengarah kepada lakilaki. Kata kerja melahirkan dan menyusui mengarah kepada gender perempuan, sedangkan membajak sawah dan menarik becak cenderung mengarah kepada gender laki-laki. Kata ganti orang atau pronominal dalam bahasa Indonesia tidak menunjukkan penanda indentitas gender. Pronomina orang pertama, orang kedua dan orang ketiga dalam bahasa Indonesia tidak membedakan perempuan dan lakilaki. Hal ini berbeda dengan bahasa Inggris bahwa pronominal menunjukkan gender, seperti she untuk perempuan dan he untuk lakilaki. Sementara itu, identitas gender secara visual gambar berupa foto, ilustrasi gambar dan karikatur.

Penelitian tentang representasi gender dengan objek buku pelajaran bahasa paling banyak dilakukan pada buku pelajaran bahasa Inggris (English as a Foreign LanguageEFL). Beberapa hasil penelitian pada bukubuku EFL menunjukkan bahwa identitas gender laki-laki lebih menonjol dan memiliki peran lebih penting daripada gender perempuan (Agni, Setyaningsih \& Sarosa, 2020; Arfiandhani, 2019; Ariyanto, 2018; Elmiana, 2019; Lee, 2019; Setyono, 2018; Sulaimani \& Elyas, 2018). Agni, Setyaningsih dan Sarosa (2020) dan Ariyanto (2018) menyatakan bahwa bias gender dalam buku pelajaran bahasa Inggris teramati dari bentuk visual dan verbal. Mereka dalam penelitiannya terhadap buku teks EFL di Indonesia menemukan adanya bias gender atas representasi laki-laki dan perempuan secara tekstual dan visual dalam buku teks EFL di Indonesia. Arfiandhani (2019) dalam penelitiannya tentang buku teks EFL tingkat SMP melaporkan adanya bias gender bahwa lakilaki digambarkan lebih berwibawa dan memiliki peran lebih penting daripada perempuan. Ketidak-setaraan gender laki-laki dan perem- 
puan juga dilaporkan dalam penelitian Elmiana (2019) bahwa gender laki-laki direpresentasi sebesar $66 \%$ dan perempuan $44 \%$. Hasil penelitian Elmiana tersebut menguatkan hasil penelitian Setyono (2018) yang menunjukkan bahwa representasi karakter laki-laki dan perempuan yang tidak setara dan tidak seimbang pada sebagian buku-buku teks EFL yang digunakan di Indonesia.

Penelitian representasi gender juga dilakukan pada buku pelajaran bahasa Arab. Hasil penelitian representasi gender pada buku pelajaran bahasa Arab menunjukkan adanya bias gender yang mengarah kepada dominasi lakilaki atas perempuan (Al-Qatawneh \& Al Rawashdeh, 2019; Foroutan, 2012; Baghdadi \& Rezaei, 2015). Al-Qatawneh dan Al Rawashdeh (2019) menemukan pemakaian bahasa maskulinitas muncul lebih banyak dibandingkan dengan pemakaian bahasa feminis dalam buku teks bahasa Arab yang dikajinya. Hal serupa dilaporkan oleh Baghdadi dan Rezaei (2015) bahwa dalam buku teks bahasa Arab yang dikajinya lebih menonjolkan maskulinitas laki-laki daripada feminisme perempuan. Ketidaksetaraan gender laki-laki dan perempuan juga ditemukan dalam penelitian Forou$\tan$ (2012) bahwa laki-laki direpresentasikan lebih dominan daripada perempuan dalam buku-buku teks pelajaran Bahasa Arab di Iran.

Kajian representasi gender dalam buku bahasa Indonesia dilakukan Hamidah (2015) yang meneliti buku pelajaran bahasa Indonesia tingkat SD, SMP, dan SMA. Hasil penelitian menunjukkan terjadi marginalisasi perempuan dan polarisasi laki-laki sebagai sosok unggul dan superior, sedangkan perempuan sebagai sosok lemah dan inferior. Hasil penelitian yang menunjuk-kan adanya ketidaksetaraan gender tersebut ditemukan setelah mengeksplorasi representasi identitas gender, representasi peran gender, dan representasi status gender. Ketidaksetaraan gender dalam buku teks bahasa Indonesia juga dilaporkan dalam penelitian Latupono dan Susanto (2019) yang mendeskripsikan representasi gender dalam buku ajar Bahasa Indonesia untuk Penutur Asing (BIPA) Sahabatku Indonesia tingkat mahir. Dalam penelitian yang bertujuan untuk mendeskripsikan visibilitas dan peran gender tersebut ditemukan laki-laki dan perempuan direpresentasikan tidak seimbang.

Berdasarkan beberapa penelitian tentang buku-buku pelajaran bahasa di atas diketahui bahwa kajian representasi gender terhadap buku teks BIPA masih sangat terbatas. Maka dari itu, perlu dilakukan penelitian lanjutan terhadap buku teks BIPA yang lain, agar representasi gender dalam buku teks BIPA lebih komprehensif. Atas dasar pertimbangan untuk memperkaya kajian representasi gender terhadap buku teks BIPA, maka penelitian ini mengkaji buku teks BIPA yang lain, yaitu Let's Speak Indonesian: Ayo Berbahasa Indonesia 1. Dipilihnya buku teks ini didasari oleh pertimbangan bahwa buku teks ini relatif baru dan digunakan di banyak institusi penyelenggara BIPA, baik di Indonesia maupun di luar negeri. Selain itu, buku teks BIPA disusun oleh pengiat dan pengajar BIPA yang tinggal di luar negeri, sehingga dimungkinkan ada perspektif berbeda dalam menyajikan isu gender dalam buku teks BIPA yang dikembangkannya. Oleh karena itu, tujuan penelitian ini adalah mendeskripsikan representasi gender secara visual, baik visual bahasa maupun visual gambar.

\section{METODE}

Penelitian ini menggunakan metode kualitatif dengan mengeksplorasi isi buku teks BIPA yang berjudul Let's Speak Indonesian: Ayo Berbahasa Indonesia 1. Buku teks BIPA ini dikembangkan oleh Ellen Rafferty, Erlin Barnard dan Lucy Suharni. Buku teks untuk ting- 
kat pemula ini diterbitkan oleh National University of Singapore (NUS) Press tahun 2014. Buku teks BIPA ini terdiri atas delapan bab yang dipaparkan mulai dari halaman satu sampai dengan halaman 202. Data penelitian berupa kata-kata dan gambar-gambar yang merepresentasikan identitas gender. Data penelitian dikumpulkan dengan cara sebagai berikut.

1. Data visual tekstual dikumpulkan dengan cara berikut.

(1) Membaca semua bagian buku yang terdiri atas bacaan, percakapan dan latihan, mulai dari bab satu sampai dengan bab delapan secara berulang dan cermat.

(2) Mencatat dan menjumlah nama-nama orang yang menunjukkan identitas gender perempuan dan laki-laki. Nama-nama yang sama hanya dicatat satu kali.

(3) Mencatat pemakaian kata-kata sapaan untuk perempuan dan laki-laki sebagai penanda identitas gender. Kata sapaan yang sama hanya dicatat satu kali.

(4) Mencatat kata-kata yang menunjukkan penanda identitas dan hubungan identitas gender.

2) Data visual atau gambar dikumpulkan dengan cara berikut.

(1) Membaca semua bagian buku mulai dari bab satu sampai dengan bab delapan secara berulang dan cermat dengan fokus mengidentifikasi bentuk visual gambar.

(2) Mencatat dan menghitung jumlah visual gambar-gambar tunggal atau individual yang berisi gambar satu lakilaki dan satu perempuan.

(3) Mencatat dan menghitung jumlah visual gambar-gambar berkelompok yang berisi laki-laki dan perempuan saja.
(4) Mencatat dan menghitung jumlah visual gambar-gambar berkelompok yang berisi laki-laki dan perempuan bersama-sama.

Selanjutnya, data yang terkumpul dianalisis dengan teori analisis isi yang meliputi: mereduksi data, menyajikan data, dan menafsirkan data, serta menjelaskan data. Miles dan Huberman (1994) mengemukakan tiga tahapan menganalisis isi data penelitian kualitatif, yaitu: (1) mereduksi data (data reduction), memaparkan data (data display), dan (3) membuat simpulan atau melakukan verifikasi (conclusion/verifying). Reduksi data dilakukan dengan mengabaikan frekuensi pemunculan data yang sama, misalnya, untuk nama-nama orang atau sapaan yang sama hanya diambil satu data saja. Penyajian data dilakukan dengan membuat klasifikasi data menjadi dua kelompok data, menghitung dan membuat rasio perbandingan. Selanjutnya penafsiran dilakukan dengan menghitung presentase representasi identitas gender. Dalam proses ini dihasilkan presentase representasi identitas gender secara tekstual dan presentase representasi identitas gender secara visual gambar yang terdapat dalam buku teks BIPA Let's Speak Indonesian: Ayo Berbahasa Indonesia 1. Tahap terakhir menjelaskan data dilakukan dengan cara mengkajinya menggunakan sejumlah referensi dalam kerangka teoretik.

\section{HASIL DAN PEMBAHASAN}

Dalam hasil dan pembahasan ini dipaparkan presentase identitas gender secara visual teks atau bahasa dan visual gambar.

\section{Presentase Representasi Identitas Gender Secara Visual Teks}

Berdasarkan bacaan, percakapan dan latihan (ayo berlatih dan ayo berkomunikasi) mulai dari bab satu sampai dengan bab dela- 
pan ditemukan delapan puluh satu (81) nama orang, dengan rincian empat puluh sembilan (49) nama perempuan dan tiga puluh dua (32) nama laki-laki. Nama-nama perempuan yang digunakan adalah: 1) Alice, 2) Amanda, 3) Amel, 4) Ana, 5) Atti, 6) Dahlia, 7) Dian, 8) Erni, 9) Grace, 10) Ida, 11) Ina, 12) Intan, 13) Ivvone, 14) Jane, 15) Jennifer, 16) Kartina, 17) Katie, 18) Lani, 19) Lastri, 20) Lia, 21) Linda, 22) Lisa, 23) Megan, 24) Mei Hua, 25) Melani, 26) Meli, 27) Mia, 28) Mita, 29) Molly, 30) Nicole, 31) Ningrum, 32) Nini, 34) Nita, 35) Pauli, 36) Pingkan, 37) Rani, 38) Ria, 39) Rina, 40) Samantha, 41) Sari, 42) Sita, 43) Siti, 44) Sri Murni, 45) Susan, 46) Susi, 47) Tati, 48) Tina, dan 49) Tuti. Sementara itu, nama-nama lakilaki yang digunakan adalah: 1) Adi, 2) Agus, 3) Andi, 4) Bob, 5) Budi, 6) Budiman, 7) Deni, 8) Doni, 9) Dulah, 10) Fernando, 11) Frederick, 12) Harun, 13) Hoffman, 14) Iwan, 15) John, 16) Karim, 17) Mark, 18) Markus, 19) Martin, 20) Pramoedya Ananta Toer, 21) Rudi, 22) Samsul, 23) Satrio, 24) Sean, 25) Sostro, 26) Surya, 27) Teguh, 28) Tomo, 29) Toni, 30) Wahyu, 31) Zainal, dan 32) Zainudin.

Nama-nama gender perempuan dan laki-laki yang digunakan dalam buku teks Ayo 1 ini tidak saja merepresentasikan nama-nama orang Indonesia, tetapi juga mencerminkan nama-nama orang Barat (western people). Misalnya, nama-nama Ana, Dahlia, Intan, Erni, dan Ida merepresentasikan nama wanita Indonesia, sedangkan Alice, Grace, Jennifer, dan Nicole merepresentasikan nama perempuan dari Barat. Hal yang sama juga tampak pada pemakaian nama laki-laki. Misalnya, Adi, Agus, Budiman, dan Harun mencerminkan nama lakilaki Indonesia. Nama Bob, Frederick, Hoffman, dan John mencerminkan nama laki- laki dari Barat. Pemakaian nama-nama perempuan dan laki-laki yang menunjukkan orang Barat atau orang dari luar negeri dan nama-nama wanita dan pria Indonesia tersebut menggambarkan adanya interaksi dan komunikasi di antar mereka. Pemakaian nama-nama orang Indonesia dan orang luar negeri dalam buku Ayo 1 menegaskan hakikat buku teks BIPA. Buku teks BIPA adalah bahan pelajaran bahasa Indonesia yang didesain secara khusus untuk pebelajar internasional (Susanto, 2020).

Berdasarkan nama-nama perempuan dan nama-nama laki-laki yang digunakan dalam buku teks BIPA Let's Speak Indonesian 1, diketahui bahwa identitas gender perempuan direpresentasikan sebesar $60 \%$ dan identitas gender laki-laki direpresentasikan sebesar 40\%. Presentase representasi gender berdasarkan pemakaian nama-nama orang yang menunjukkan gender laki-laki dan perempuan dirangkum dalam tabel 1 berikut.

Tabel 1: Presentase pemakaian nama-nama orang

\begin{tabular}{ccc}
\hline $\begin{array}{l}\text { Jumlah nama } \\
\text { orang }\end{array}$ & $\begin{array}{l}\text { Jumlah nama } \\
\text { laki-laki }\end{array}$ & $\begin{array}{l}\text { Jumlah nama } \\
\text { perempuan }\end{array}$ \\
\hline 81 & 32 & 49 \\
\hline Persentase & $40 \%$ & $60 \%$ \\
\hline
\end{tabular}

Jumlah munculnya nama laki-laki dan perempuan menjadi indikator sebuah representasi gender dalam buku teks. Berdasarkan jumlah munculnya gender laki-laki dan perempuan dalam buku teks yang diteliti menunjukkan perbedaan. Temuan penelitian yang menunjukkan gender perempuan direpresentasikan lebih besar daripada gender laki-laki ini sangat menarik dan dapat dikatakan baru. Temuan penelitian ini menolak hasil penelitian representasi gender sebelumnya yang menonjolkan identitas gender 
laki-laki. Temuan ini berbeda dengan temuan penelitian representasi gender dalam bu$\mathrm{ku}$ teks sebelum yang rata-rata menunjukkan adanya bias gender. Hasil penelitian cenderung menunjukkan bias gender, gender perempuan direpresentasikan tidak seimbang dibandingkan gender laki-laki (Al-Qatawneh \& Al Rawashdeh, 2019; Ariyanto, 2018; Baghdadi \& Rezaei, 2015; Fahriany, Alek \& Wekke, 2019; Foroutan, 2012).Temuan penelitian yang menunjuk-kan presentase gender perempuan lebih besar dibandingkan dengan presentase gender laki-laki kemungkinan besar disebabkan oleh ketiga penulis buku teks ini yang kesemuanya perempuan dan berlatar belakang Amerika. Secara sadar atau bawah sadar pemahaman dan pengalaman penulis, termasuk keyakinan penulis terhadap gender dicerminkan dalam buku teks BIPA Lets Speak Indonesian ini.

Selain penggunaan nama-nama orang, penanda identitas gender juga ditunjukkan oleh pemakaian kosakata sapaan gender perempuan dan gender laki-laki. Bentuk sapaan penanda identitas gender yang digunakan dalam buku teks ini berjumlah dua belas (12) kosakata, dengan rincian enam (6) sapaan perempuan dan enam (6) sapaan lakilaki. Keenam sapaan perempuan yang digunakan adalah: 1) Bibi, 2) $\mathrm{Bu}, 3) \mathrm{Ibu}, 4)$ Mbak, 5) Nenek, dan 6) Tante. Sementara itu, bentuk sapaan penanda identitas gender laki-laki adalah: 1) Bapak, 2) Kakek, 3) Om, 4) Pak, 5) Paman, dan 6) Mas. Berdasarkan jumlah sapaan untuk perempuan dan namanama laki-laki yang digunakan dalam buku teks BIPA Let's Speak Indonesian 1, diketahui bahwa identitas gender perempuan direpresentasikan sebesar $50 \%$ dan identitas gender laki-laki direpresentasikan sebesar $50 \%$. Presentase representasi gender berda- sarkan pemakaian sapaan kekerabatan yang menunjukkan gender laki-laki dan perempuan dirangkum dalam tabel 2 berikut.

Tabel 2: Presentase representasi pemakaian sapaan

\begin{tabular}{ccc}
\hline $\begin{array}{l}\text { Jumlah sapaan } \\
\text { kekerabatan }\end{array}$ & $\begin{array}{c}\text { Sapaan kekera- } \\
\text { batan laki-laki }\end{array}$ & $\begin{array}{c}\text { Sapaan kekera- } \\
\text { batan perempuan }\end{array}$ \\
\hline 12 & 6 & 6 \\
\hline Persentase & $50 \%$ & $50 \%$ \\
\hline
\end{tabular}

Ditemukan juga kosakata yang menunjukkan penanda identitas gender perempuan dan laki-laki dan status hubungan gender. Jumlah kosakata penanda indentitas gender sebanyak 10 kosakata gender perempuan dan laki-laki. Penanda identitas gender dan status hubungan dengan perempuan ada lima kosakata (5), yaitu: 1) perempuan, 2) wanita, 3) istri, 4) adik perempuan, dan 5) kakak perempuan. Sementara itu, penanda status gender lakilaki juga ada lima (5) kosakata, yaitu: 1) Pria, 2) laki-laki, 3) suami, 4) adik laki-laki, dan 5) kakak laki-laki. Berdasarkan jumlah kosakata yang menunjukkan penanda status gender perempuan dan gender laki-laki ditemukan bahwa identitas gender perempuan direpresentasikan dalam lima kosakata atau sebesar 50\% dan identitas gender laki-laki tercermin dalam lima kosakata atau sebesar 50\%. Presentase representasi gender berdasarkan pemakaian penanda hubungan kekerabatan dan sosial yang menunjukkan gender laki-laki dan perempuan dirangkum dalam tabel 3 berikut.

Tabel 3: Presentase representasi penanda identitas gender dan hubungannya

\begin{tabular}{lcc}
\hline $\begin{array}{l}\text { Jumlah pe- } \\
\text { makaian penanda } \\
\text { identitas gender }\end{array}$ & $\begin{array}{l}\text { Penanda identi- } \\
\text { tas laki-laki }\end{array}$ & $\begin{array}{l}\text { Penanda iden- } \\
\text { titas Perem- } \\
\text { puan }\end{array}$ \\
\hline 10 & 5 & 5 \\
\hline Persentase & $50 \%$ & $50 \%$
\end{tabular}


Presentase Representasi Identitas Gender Secara Visual Gambar

Secara visual representasi gender dalam buku teks BIPA Let's Speak Indonesian diwujudkan dalam bentuk gambar dan/atau foto. Berdasarkan gambar dan/atau foto yang disajikan dalam buku teks tersebut diketahui bahwa gender perempuan dan gender laki-laki diwujudkan dalam lima bentuk. Kelima bentuk tersebut adalah gambar dan/atau 1) tunggal perempuan, 2) tunggal laki-laki, 3) kelompok yang berisi laki-laki saja, 4) kelompok yang berisi perempuan saja, dan 5) kelompok yang berisi laki-laki dan perempuan. Contoh data visual yang berupa gambar dan/atau foto sebagai berikut.

1) Gambar perempuan tunggal:

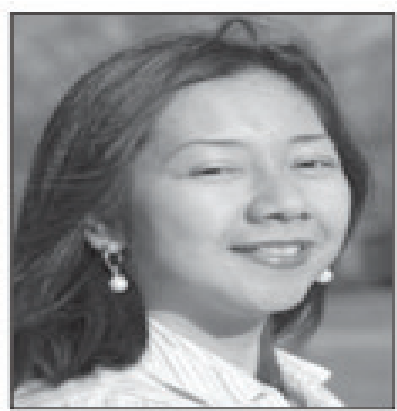

cantik/cakep

(Pelajaran 2 hal 37)

2) Gambar laki-laki tunggal:

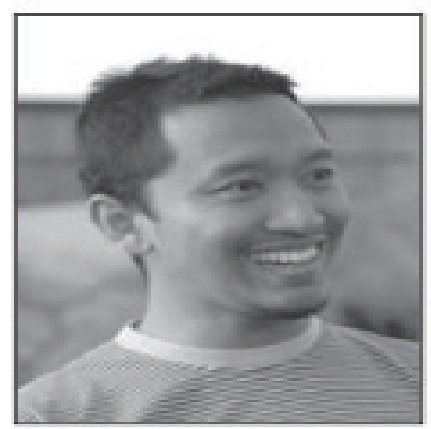

tampan/cakep

(Pelajaran 2 hal 37)
3) Gambar kelompok berisi perempuan saja:

Pelajaran 1.1: Berkenalan

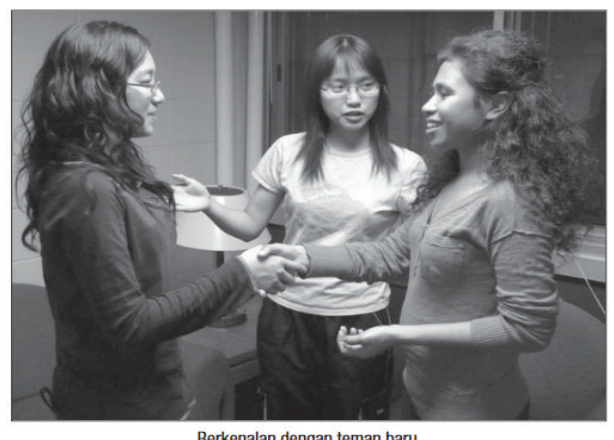

(Pelajaran 1 hal 2)

4) Gambar kelompok berisi laki-laki saja:

Pelajaran 2.2: Teman dan Tetangga

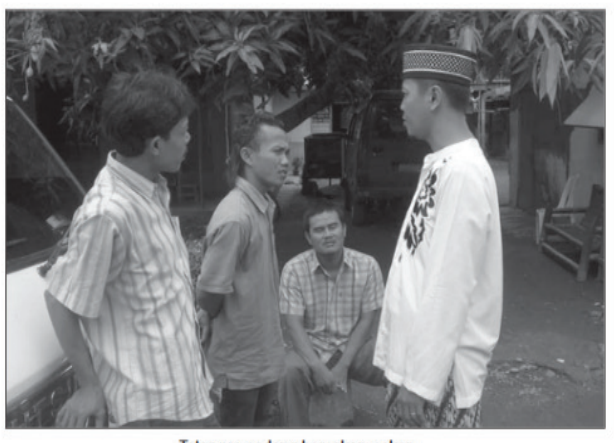

Tetangga sedang bercakap-cakap.

(Pelajaran 2 hal 36)

5) Gambar kelompok berisi perempuan dan laki-laki:

Bab 2

Keluarga dan Teman-Teman

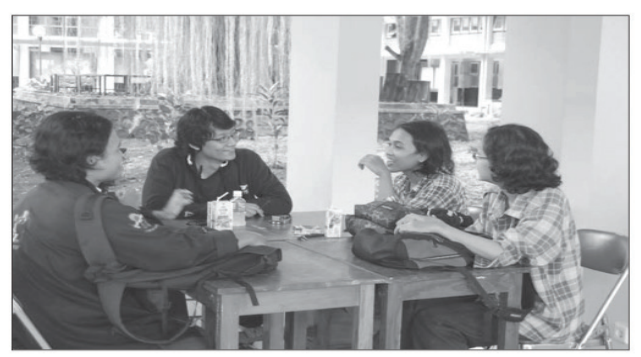

(Pelajaran 2 hal 25) 
Representasi gender perempuan dan gender laki-laki berdasarkan lima pola analisis di atas diperoleh tiga hasil sebagai berikut. Jumlah gambar tunggal atau individual yang menunjukkan identitas gender sebanyak 62 gambar, dengan rincian gambar perempuan sebanyak 35 (56\%) dan gambar laki-laki sebanyak 27 (44\%). Gambar secara berkelompok berjumlah 52 gambar, dengan rincian gambar kelompok perempuan dan laki-laki masing-masing sebanyak 10 gambar. Dari kelompok ini diketahui bahwa gambar kelompok yang berisi perempuan dan laki-laki saja besarnya sama, yaitu 50\% dan 50\%. Gambar kelompok yang segender berjumlah 20 gambar (38\%) dan jumlah kelompok yang berisi gender berbeda sebanyak 32 gambar (62\%). Ringkasan jumlah gambar berdasarkan identitas gender perempuan dan laki-laki secara individual dan kelompok disajikan dalam tabel 4 berikut.

Tabel 4: Sebaran Visual Gambar Identitas Gender

\begin{tabular}{|c|c|c|c|c|c|}
\hline \multirow[t]{2}{*}{ Gender } & \multicolumn{2}{|c|}{$\begin{array}{l}\text { Gambar } \\
\text { Tunggal }\end{array}$} & \multicolumn{3}{|c|}{ Gambar Kelompok } \\
\hline & $\mathrm{P}$ & $\mathrm{L}$ & $\mathrm{P}$ & $\mathrm{L}$ & P \& L \\
\hline Jumlah & 35 & 27 & 10 & 10 & 32 \\
\hline \multirow[t]{2}{*}{ Persentase } & $56 \%$ & $44 \%$ & $50 \%$ & $50 \%$ & \\
\hline & & & \multicolumn{2}{|c|}{$38 \%$} & $62 \%$ \\
\hline
\end{tabular}

Temuan penelitian bahwa secara visual teks representasi nama laki-laki sebesar $40 \%$ dan perempuan sebesar $60 \%$, gambar perempuan tunggal 56\% dan gambar laki-laki 44\% adalah sesuatu yang baru dan menarik. Dianggap baru karena hasil penelitian berbeda bahkan mementahkan hasil penelitian sebelumnya yang mayoritas menunjukkan bias gender laki-laki atas perempuan. Dalam buku teks bahasa Arab (Al-Qatawneh \& Al Rawashdeh, 2019; Foroutan, 2012; Baghdadi \& Rezaei,
2015) menemukan adanya dominasi laki-laki atas perempuan dan pemakaian kata-kata maskulin yang lebih banyak daripada feminim. Dalam buku teks bahasa Inggris juga ditemukan ada bias gender laki-laki atas perempuan dengan ditampilkannya laki-laki lebih dominan daripada perempuan (Ariyanto, 2018; Setyono, 2018; Sulaimani \& Elyas, 2018). Dalam buku teks bahasa Indonesia juga ditemukan adanya ketidaksetaraan gender (Hamidah, 2015). Bahkan dalam buku teks BIPA (Latupono \& Susanto, 2019) juga melaporkan adanya ketidakadilan dalam merepresentasikan gender laki-laki dan perempuan. Temuan penelitian yang menunjukkan representasi gender perempuan yang lebih banyak ini dapat ditafsirkan mengakhiri dominasi laki-laki atas perempuan dalam sebuah buku teks.

Temuan ini juga menarik karena dari buku teks Ayo 1 ini pengguna bisa mendapatkan perspektif lain tentang masyarakat Indonesia. Buku teks BIPA Ayo 1 ini dapat memberikan informasi kepada mahasiswa asing yang belajar bahasa Indonesia bahwa secara budaya, masyarakat Indonesia memiliki kesadaran gender. Guru yang menggunakan bahan ajar ini juga mendapatkan inside baru bahwa buku teks bahasa tidak semata-mata berisi pelajaran bahasa, tetapi lebih luas dari itu. Buku teks BIPA juga berisi nilai-nilai universal tentang Indonesia. Buku teks BIPA sebagai buku pelajaran bahasa memuat nilai sosial budaya (Keplinger, Kowal \& Mäkiö, 2016), religiusitas, ideologi, dan nilai-nilai lainnya termasuk perspektif gender.

Presentase 50\% untuk gender laki-laki dan $50 \%$ untuk gender perempuan pada penggunaan sapaan, identitas penanda hubungan, dan visual gambar yang berisi laki-laki atau perempuan saja dapat dimaknai sebagai tidak ada yang lebih dominan, mereka saja dan pe- 
rempuan saja menunjukkan bahwa mereka memiliki kedudukan yang setara. Presentasi gender perempuan dan laki-laki yang dimanifestasikan $50 \%$ dan 50\% menunjukkan bahwa di antara kedua gender tersebut tidak ada yang lebih kuat, lebih mendominasi, dan lebih berkuasa. Gender perempuan dan laki-laki dalam budaya Indonesia memiliki kedudukan yang setara, sederajat, dan seimbang. Perempuan dan laki-laki dalam budaya Indonesia ditampilkan sebagai sebagai pribadi yang mandiri, merdeka, dan bebas. Temuan penelitian memberikan perspektif yang baru tentang teori gender bahwa bahasa Indonesia sebagai salah satu wujud budaya Indonesia memiliki perspektif kesadaran gender dan strategi mengartikulasikan gender secara berbeda. Perspektif toeritik dan praktik gender dalam budaya Barat dan budaya Indonesia tidak sama.

Representasi gender dalam gambar individual dan gambar kelompok dalam buku Ayo 1 ini juga menunjukkan temuan yang menarik untuk dibahas. Gambar kelompok yang berisi laki-laki dan perempuan yang berjumlah 32 gambar atau sebesarnya $62 \%$ dan gambar kelompok yang berisi perempuan saja atau lakilaki saja yang berjumlah 20 gambar atau sebesar 38\% merupakan representasi sosiokultural masyarakat Indonesia. Kelompok perempuan saja dan laki-laki saja tidak mengekslusifkan diri. Perempuan dan laki-laki dalam masyarakat Indonesia berbaur dan saling bekerja sama. Laki-laki dan perempuan di Indonesia sebagai kelompok yang ajur ajer, menyatu padu tanpa memandang perbedaan jenis kelamin. Perempuan dan laki-laki tidak mengekslusifkan diri dan tidak memilih pergaulan dari sudut pandang gender. Temuan penelitian ini memberikan gambaran bahwa pengembang bahan ajar bahasa merupakan agen of change atau agen perubahan untuk menyuarakan nilai-nilai gender suatu masyarakat atau bangsa kepada masyakarat di luar kelompoknya atau kepada bangsa lain.

Temuan penelitian menunjukkan bahwa gender laki-laki dalam buku teks Ayo 1 tidak lebih dominan daripada gender perempuan berimplikasi secara pedagogis dalam pembelajaran BIPA.Temuan ini berbeda dengan temuan penelitian sebelumnya yang menyatakan lakilaki lebih dominan daripada perempuan (Agni, Setyaningsih \& Sarosa, 2020; Arfiandhani, 2019, Elmiana, 2019; Lee, 2019). Implikasi secara pedagogis tersebut pada pengembangan kurikulum, silabus, pengembangan bahan ajar dan praktik kegiatan belajar mengajar di kelas BIPA. Pengembangan kurikulum, silabus, dan bahan ajar, serta guru BIPA perlu memahami hakikat kesetaraan gender dan mempraktikkan pemahaman tersebut dalam mengembangkan kurikulum. Silabus dan bahan ajar BIPA. Oleh karena itu, mereka perlu adil dalam memasukkan nama-nama orang, kata benda, kata sifat dan kata kerja, serta penanda identitas gender yang lainnya. Dosen BIPA secara strategis perlu mengarahkan jenis tugas dan menentukan cara tugas tersebut dikerjakan oleh mahasiswa. Penentuan jenis tugas dan cara tugas tersebut dikerjakan oleh mahasiswa merupakan praktik baik dalam menanamkan nilai-nilai kesetaraan gender kepada mahasiswa. Pengembang kurikulum, silabus, dan bahan ajar, serta dosen BIPA adalah agen of change yang strategis untuk mengkomunikasikan dan mempromosikan budaya Indonesia, termasuk praktik gender di Indonesia kepada mahasiswa internasional.

\section{SIMPULAN}

Representasi identitas gender dalam buku teks BIPA Let's Speak Indonesian: Ayo Berbahasa Indonesia 1 dapat diamati secara visual, baik dalam bentuk teks maupun gambar. Bentuk visual identitas gender yang berwujud bahasa atau teks, berupa pemakaian nama-nama laki-laki 
dan perempuan, sapaan, dan kata penanda identitas gender dan hubungannya dengan gender. Bentuk visual gambar berupa gambar laki-laki tunggal, gambar perempuan tunggal, gambar kelompok perempuan saja, dan gambar kelompok laki-laki saja, serta gambar berkelompok yang berisi laki-laki dan perempuan. Pemakaian bentuk visual yang berupa teks dan gambar merupakan strategi pilihan pengembang buku teks BIPA untuk representasi gender perempuan dan lakilaki.

Berdasarkan temuan penelitian dan pembahasan diketahui bahwa secara visual teks namanama orang yang digunakan, gender perempuan direpresentasikan sebesar $60 \%$ dan laki-laki 40\%. Dari pemakaian kata sapaan kekerabatan, gender perempuan dan laki-laki direpresentasikan sama, yaitu $50 \%$ dan $50 \%$. Dari pemakaian penanda identitas dan hubungan, gender perempuan memiliki presentase $50 \%$ dan gender lakilaki 50\%. Secara visual gambar tercermin bahwa gambar individual perempuan memiliki 56\% dan laki-laki 44\%. Gambar kelompok perempuan saja presentasenya $50 \%$ dan gambar kelompok laki-laki saja 50\%. Gambar kelompok yang beranggotakan perempuan dan laki-laki saja $38 \%$ dan gambar kelompok yang beranggotakan perempuan dan laki-laki direpresentasikan sebesar $68 \%$. Berdasarkan presentase representasi gender dapat dikemukakan bahwa gender lakilaki tidak lebih dominan daripada gender perempuan. Oleh karena itu, dapat disimpulkan bahwa buku teks Ayo 1 merepresentasikan kesetaraan gender perempuan dan laki-laki.

Melalui buku teks BIPA, mahasiswa asing tidak saja belajar bahasa Indonesia, tetapi mereka juga belajar aspek budaya, ekonomi, politik, sosial dan nilai-nilai lainnya yang berlaku di masyarakat Indonesia. Oleh karena itu, pengembang buku teks bahasa direkomendasikan untuk mengintegrasikan materi keterampilan berbahasa dengan aspek-aspek lain di luar materi keba- hasaan. Hal ini dapat dipahami karena buku teks bahasa tidak hanya berisi materi kebahasaan saja, tetapi juga berisi pengetahuan dan nilai-nilai lainnya yang menggambarkan jiwa masyarakat pemakai bahasa tersebut. Secara pedagodis, pengajar yang menggunakan buku teks ini disarankan untuk lebih sering memberikan tugas kelompok daripada tugas individual. Selain itu, untuk menghindari terjadinya eksklusifitas gender tertertu, seharusnya dosen mengarahkan mahasiswa untuk membentuk kelompok yang anggotanya terdiri atas laki-laki dan perempuan, bukan kelompok berisi laki-laki saja atau perempuan saja.

\section{DAFTAR PUSTAKA}

Agni, Z. A., Setyaningsih, E., \& Sarosa, T. 2020. Examining gender representa-tion in an Indonesian EFL textbook. Register Journal, 13(1), 183-207.

Al-Qatawneh, S., \& Al Rawashdeh, A. 2019. Gender representation in the Arabic language textbook for the ninth grade approved by the Ministry of Education for use in schools in the United Arab Emirates (UAE). Studies in Educational Evaluation, 60, 90-98.

Arfiandhani, P. 2019. Gender Representa-tion in English as A Foreign Language (EFL) Textbooks for Senior High School in Indonesia. Prominent, 2(1).

Ariyanto, S. 2018. A portrait of gender bias in the prescribed Indonesian ELT textbook for junior high school students. Sexuality \& culture, 22(4), 1054-1076.

Baghdadi, M., \& Rezaei, A. 2015. Gender representation in English and Arabic foreign language textbooks in Iran: A comparative approach. Journal of International Women's Studies, 16 (3), 16-32.

Bahman, M., \& Rahimi, A. (2010). Gender representation in EFL materials: An anal- 
ysis of English textbooks of Iranian high schools. Procedia-Social and Behavioral Sciences, 9, 273-277.

Calvert, A. 2014. You are what you (m) eat: Explorations of meat-eating, masculinity and masquerade. Journal of International Women's Studies, 16(1), 18-33.

Elmiana, D. S. 2019. Pedagogical representation of visual images in EFL textbooks: a multimodal perspective. Pedagogy, Culture \& Society, 27(4), 613-628.

Fahriany, F., Alek, A., \& Wekke, I. S. 2019. Gender Representation in English Textbooks for Islamic Junior High School Students. Kafaah: Journal of Gender Studies, 8(2), 149-168.

Foroutan, Y. 2012. Gender representation in school textbooks in Iran: The place of languages. Current Sociology, 60(6), 771-787.

Hamidah, S.C. 2015. Representasi Ideologi Gender dalam Buku Teks Bahasa Indonesia. Disertasi dan tesis Program Pascasarjana UM.

Jannati, S. 2015. Gender representation in EFL textbooks: A case of ILI pre-intermediate series. Journal of Applied Linguistics and Language Research, 2(3), 211-222.

Keplinger, A., Kowal, J., \& Mäkiö, J. 2016. Gender and organizational citizenship behavior of information technology users in Poland and Germany. In Proceedings of the Twenty-second Americas Conference on Information Systems (AMCIS), San Diego, California, USA.

Lakoff, R. 2003. Language, gender, and politics: Putting "women" and "power" in the same sentence. The Handbook of Language and Gender, 160-178.

Latupono, R.M \& Susanto, G. 2019. Representasi Gender dalam Buku Ajar BIPA Saha- batku Indonesia Tingkat Mahir. Jurnal Kajian Bahasa, Sastra Indonesia, dan Pembelajarannya Volume 3 Nomor 1.

Lee, J. F. 2019. In the pursuit of a genderequal society: do Japanese EFL textbooks play a role? Journal of Gender Studies, 28(2), 204-217.

Lestariyana, R. P. D., Widodo, H. P., \& Sulistiyo, U. 2020. Female Repre-sentation in Government-Mandated English Language Textbooks Used in Indonesian Junior High Schools. Sexuality \& Culture, 24(4).

Liu, J. 2013. Visual Images Interpretive Strategies in Multimodal Texts. Journal of Language Teaching and Research, 4(6). https://doi

Miles, M. B., \& Huberman, A. M. 1994. Qualitative data analysis: An expanded sourcebook. Sage.

Rafferty, Ellen, Barnard, Erlin, \& Suharni, Lucy. 2014. Let's Speak Indonesian: Ayo Berbahasa Indonesia 1. Nus Press Singapore.

Setyono, B. 2018. The portrayal of women in nationally-endorsed English as a foreign language (EFL) textbooks for senior high school students in Indonesia. Sexuality and Culture, 22, 1077-1093.

Sulaimani, A., \& Elyas, T. 2018. A glocalized or globalized edition? Contextualizing gender representa-tion in EFL textbooks in Saudi Arabia: A critical discourse analysis perspective. In Conceptual Shifts and Contextualized Practices in Education for Glocal Interaction (p. 55-76). Springer, Singapore.

Susanto, G., Suparmi \& Yulia Rahayu, E. (2020). The Emotional Geography of International Students in Online Bahasa Indonesia Learning during the COVID-19 Pandemic. Journal of International Students, 10(S3), 161-179. 